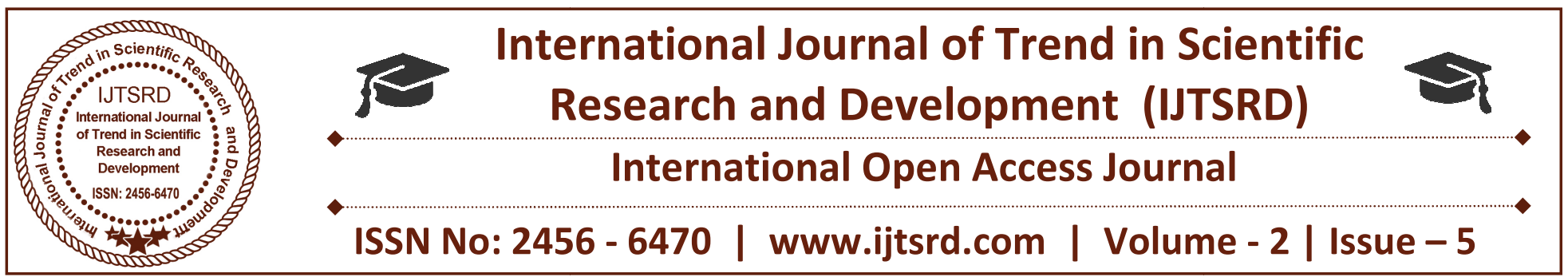

\title{
Control of Three-Phase Shunt Active Power Filter (SAPF) by Instantaneous Reactive Power Theory
}

\author{
Prof. Nilesh Chamat \\ Assistant Professor, Department of Electrical Engineering, \\ Ballarpur Institute of Technology, Ballarpur, Chandrapur, Maharashtra, India
}

\begin{abstract}
Use of nonlinear loads has been increased in large extent in industries now-a-days which injects harmonic currents in supply system. These harmonics creates power quality issue. Shunt Active Power Filter (SAPF) is the popular and efficient solution to reduce these harmonics. SAPF can overcome voltage sag, eliminate harmonics and improves power factor. SAPF reduces total harmonic distortion (THD) to acceptable level. Reference current generation is the heart of APF. Reference current generation using instantaneous reactive power (IRP) theory is presented in this paper. IRP theory is widely used to control active power filters (APFs). Modeling of this technique is implemented in MATLAB/simulink.
\end{abstract}

Keywords: Isolation; SAPF, Power quality, IRP Theory, THD, MATLAB/simulink

\section{INTRODUCTION}

Power quality issue is becoming very serious now-adays. This is because nonlinear loads such as electrical machines, static power converters, electric arc furnaces, etc. which mainly lead to harmonic disturbances in power lines. Also power electronic equipments for human comfort plays major role in it. Although these power electronic equipments make our life convenient, it injects lot of harmonic current to the supply system and affects power factor [1]. Conventionally, passive LC filters have been used to eliminate line current harmonics and thereby increase the load power factor. Tuned passive filters are very effective for the elimination of specific harmonic components but has some drawbacks, such as

$>$ Fixed Compensation,

$>$ Resonance,

$>$ huge size
They may cause series and load resonances in the system. Also its performance depends on load, it get affected significantly due to the variation in the filter component values, filter component tolerance, source impedance, and frequency of ac source [1]. The main objective of power system is generation and distribution of clean and pollution free power to its end users. But now-a-days quality of power is being deteriorated. There are many reasons for this. Some of them are like internally connected systems, widely increasing industrialization, increasing use of nonlinear loads, use of power electronic devices for human comfort, etc. some of the power quality issues faced by end users are interruptions, sagging, switching transients, flickering. In addition to all this, with the use of microprocessor based controlling devices, protective devices become more sensitive towards power quality than in past.

Following are some of the disturbances which are common in affecting power quality of the system:

$>$ Transients

> Sag and Swell

V Variation in voltage

Harmonics

Shunt Active Power Filter (SAPF) is the effective solution to these problems. Active Filters can be designed to achieve following goals [2]:

$>$ Harmonic Compensation

$>$ Harmonic Isolation

$>$ Reactive power compensation

$>$ Voltage regulation

Out of three system based configurations of APF; here we are interested in Shunt Active Power Filter (SAPF). The Active filters overcome the problem 
occurring in the passive filter. Major Advantage of Active Filter over Passive Filter is that it can be controlled to compensate harmonics such that Total Harmonic Distortion (THD) lower than 5\% at the PCC can effectively be achieved. SAPF is shown in fig 1 . The reference current generation is like heart for APF.

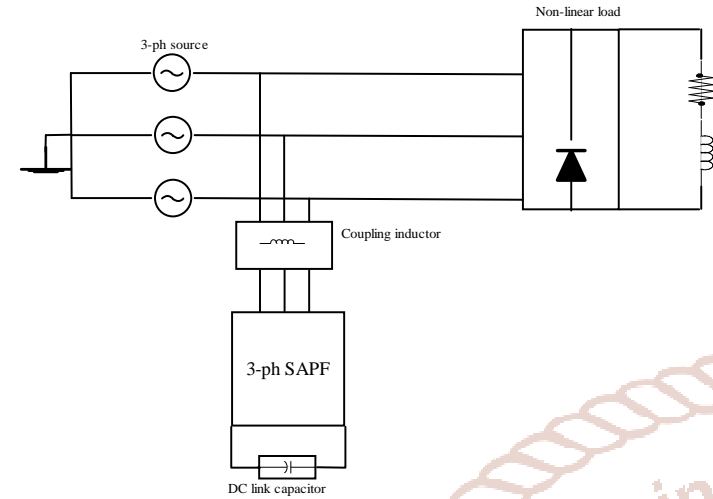

Figure1. Basic structure of SAPF

In this paper reference current generation using IRP theory is presented.

\section{LITERATURE REVIEW}

In [3] different approaches such as notch filter, (Newman et al., 2002), scalar control, (Chandra etal., 2000), instantaneous reactive power theory(IRP), (Furuhashi et al., 1990, Akagi et al., 2007), synchronous detection method, (Chen et al., 1993), synchronous d-q frame method(SRF), (Mendalek et al., 2003), flux-based control, (Bhattacharya et al., 1996), and closed loop PI, (Bhattacharya et al., 1996), internal model control, (Marconi et al., 2007), and sliding mode control, (Saetieo et al., 1995), can be used to improve the active filter performance. Also, the direct power control method has found application in active filters, (Chen \& Joós, 2008). Specific harmonics can be cancelled out in the grid using the selective harmonic elimination method (Lascu et al., 2007). In all cases, the goal is to design a simple but robust control system for the filter. The newly applied method in Active filter is On-off controller, neural network controller, Fuzzy logic controller. The application of artificial intelligence is growing fast in the area of power sectors. The artificial neural network (ANN) is considered as a new tool to design control circuitry for power-quality (PQ) devices. The first neural network model is designed by McCulloch and Pitts (1943). In[9] a new learning algorithm for linear neural networks (ADALINE) Widrow \& Hoff (1960). In [4] Adaline based control method is presented and it is compared against traditional PID controller based approach. With the use of this artificial neural network algorithm, the functionality of the shunt active filter is enhanced.

\section{CONTROL STRATEGY}

Key factor for successful implementation of SAPF is Control strategy. In this paper SAPF is controlled using instantaneous reactive power theory (IRP) or p$\mathrm{q}$ theory. The instantaneous active and reactive power theory has been widely used method for estimation of compensating signals. Akagi in 1984 have presented a new instantaneous reactive power compensator comprising switching devices without energy storage components, based on this theory and has since been the subject of various interpretations and improvements. This theory is further used for the control of shunt and series filters. The $p$ - $q$ theory is based on the $\alpha \beta o$ transformation which transforms three phase voltages and currents into the $\alpha \beta 0$ stationary reference frame. From these transformed quantities, instantaneous real and reactive power of the load is calculated which consists of DC component and an oscillating component. The oscillating component is extracted using high pass filter and taking inverse $\alpha-\beta$ transformation compensating command signals in terms of either currents or voltages are derived.

Reference current generation is the heart of APF. There are so many techniques for reference current generation. Figure 3 shown below gives basic block diagram of reference current generation. We are using three different techniques here. For reference current generation, active and reactive power is being calculated from three phase currents and voltages. Later on as per control technique power is being transformed. Average power is being calculated from power obtained. Then it is compared with voltage reference obtained from PID controller of inverter. Signals obtained are further compared with source currents. Finally obtained currents are the reference currents. These reference currents are further given to current controlling circuit for PWM signal generations. Further these PWM signals are given to inverter for harmonic compensation

To deal with instantaneous voltages and currents in three phase circuits mathematically, it is adequate to express their quantities as the instantaneous space vectors. For simplicity, the three-phase voltages and currents excluding zero-phase sequence components will be considered in the following. In a-b-c coordinates $\mathrm{a}, \mathrm{b}$, and $\mathrm{c}$ axes are fixed on the same 
plane, apart from each other by $2 \pi / 3$. In this method, three phase voltages and currents are converted into $\alpha \beta 0$ using following equations. Block diagram of control strategy is shown in figure 2 below. Using IRP theory, reference current will be generated. These reference currents will be further used to generate gate pulses for inverter. The basic principle of reference current generation is shown in figure 3 below.

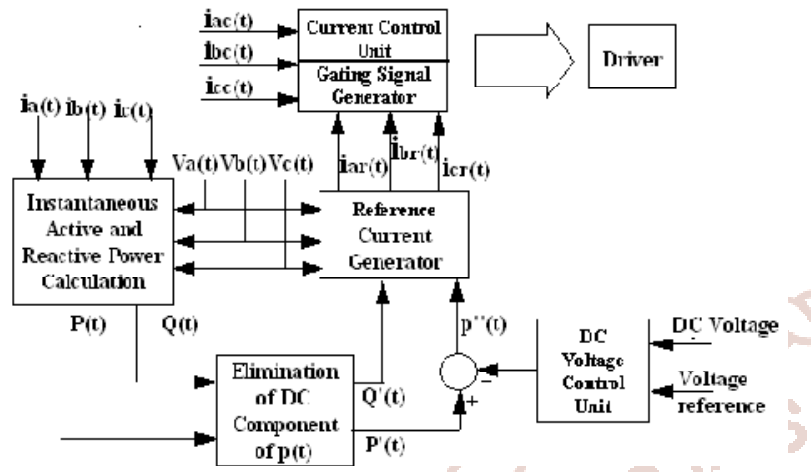

Figure2. Control strategy of SAPF

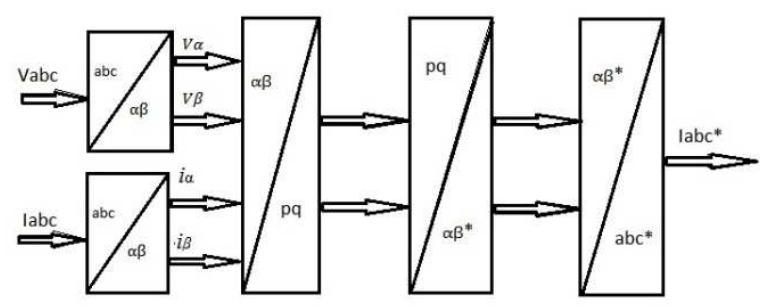

Figure3. Reference current generation

It is now widely used to estimate compensating signals. It is also known as Clark Transformation for three phase current and voltages [5].

This method is based on transformation of three phase voltage and current signals into $\alpha \beta 0$ stationary reference frame. In this method, first three phase voltages and currents are converted into $\alpha \beta 0$ using following equations [2],

$$
\begin{aligned}
& i \alpha \beta=\sqrt{2 / 3}\left[\begin{array}{ccc}
1 & -1 / 2 & -1 / 2 \\
0 & \sqrt{3} / 2 & -\sqrt{3} / 2 \\
1 / \sqrt{2} & 1 / \sqrt{2} & 1 / \sqrt{2}
\end{array}\right] \text { iabc } \\
& V \alpha \beta=\sqrt{2 / 3}\left[\begin{array}{ccc}
1 & -1 / 2 & -1 / 2 \\
0 & \sqrt{3} / 2 & -\sqrt{3} / 2 \\
1 / \sqrt{2} & 1 / \sqrt{2} & 1 / \sqrt{2}
\end{array}\right] . V a b c
\end{aligned}
$$

Active and reactive power for three phase system can be given as following equations (3) and (4),

$$
p=v \alpha \cdot i \alpha+v \beta \cdot i \beta
$$

$$
q=v \alpha \cdot i \beta-i \alpha \cdot v \beta
$$

Matrix form of the above equations can be given as eq. (5),

$$
\left[\begin{array}{l}
p \\
q
\end{array}\right]=\left[\begin{array}{cc}
V \alpha & V \beta \\
-V \beta & V \alpha
\end{array}\right] \cdot\left[\begin{array}{l}
i \alpha \\
i \beta
\end{array}\right]
$$

Active and reactive power can be separated in two parts i.e. $\mathrm{AC}$ and $\mathrm{DC}$ as following equation (6) and (7),

$$
\begin{aligned}
& \mathrm{P}=\bar{p}+\tilde{p} \\
& \mathrm{q}=\bar{q}+\tilde{q}
\end{aligned}
$$

In order to get DC part of active and reactive power, $p$ and $\mathrm{q}$ signals need to be passed through low pass filter. It will filter out high frequency components and will give expected signals i.e. fundamental part.

As per $p$-q theory, active power is given by DC part of $\alpha-\beta$ reference current, it can be given as following equation (8),

$$
\operatorname{i\alpha } \beta^{*}=\frac{V \alpha}{V \alpha^{2}+V \beta^{2}}\left[\begin{array}{cc}
V \alpha & V \beta \\
-V \beta & V \alpha
\end{array}\right]\left[\begin{array}{l}
p \\
q
\end{array}\right]
$$

Further, actual three phase reference currents can be given as following equation (9),

$$
\text { iabc }^{*}=\sqrt{2 / 3}\left[\begin{array}{cc}
1 & 0 \\
-1 / 2 & \sqrt{3} / 2 \\
-1 / 2 & -\sqrt{3} / 2
\end{array}\right] \cdot i \alpha \beta^{*}
$$

These currents are compared with source currents and obtained error is processed through PI to generate reference current for APF. IRP theory has advantage that obtained fundamental components of active and reactive power are DC quantities. As these signals are DC quantities, $\alpha \beta \square \square$ reference frame is unaffected by any phase shift introduced by low pass filter.

\section{Switching Signal generation}

There are different techniques for switching signal generation for controlling shunt active power filters based on current controller or voltage controller. Hysteresis controllers utilize some type of hysteresis in the comparison of the line currents to the current references. The compensating currents are compared 
with the reference currents by using hysteresis comparators to generate the six switching pulses. These pulses are used to turn on and turn off IGBTs. Figure 4 shows the simulation models for Switching Signal Generation Technique.

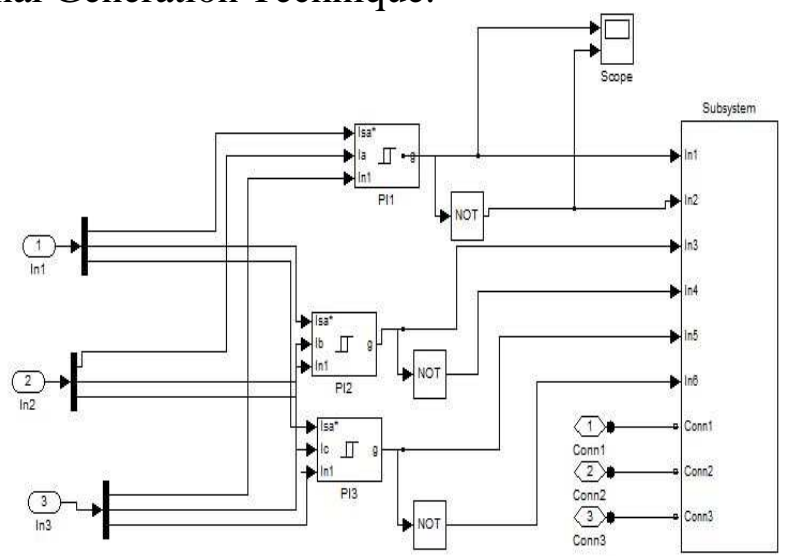

Figure4. Hysteresis Current Controller

\section{SIMULATION RESULTS}

The proposed system is simulated in MATLAB/simulink along with the control technique proposed in figure 2 and 3 . The figure 5 shown below gives the shunt active power filter system simulated in MATLAB/Simulink along with control technique, non linear load and gate pulse generation This load draws a highly nonlinear current rich in harmonics with a substantial reactive power requirement. A three phase, VSI-based shunt AF is connected to the system for reactive power compensation and harmonics elimination. Figure 5 shows the basic simulation model of SAPF system that correlates to the system configuration shown in Figure 1 in terms of source, load, SAPF, and control blocks. This SAPF model is simulated with the above described $\operatorname{IRP}(p-q)$ theory.

Figure 5 shows the MATLAB simulation diagram of SAPF. It is connected through $400 \mathrm{~V}$ phase to phase voltages. A load side is non linear one having R-L-C components in it which will create harmonics in source current. SAPF is connected to supply system through very small coupling inductor. Inputs to the reference current generation are source voltage, source current and output of PI controller. It is closed loop system where feedback is given through PI controller. Reference currents are generated using P-Q theory block as shown in figure 5. These generated reference currents will be given to the hysteresis current controller shown in figure 4 to generate PWM pulses. These generated pulses will be used to trigger inverter switches. In hysteresis current controller (HCC) three inputs are there like source current, reference current and one feedback signal. From HCC six signals will be given to the six switches of inverter. Further inverter will give 3 filter currents. These filter currents will be injected in the system through coupling inductor at point of common coupling (PCC). The simulation is performed on three phase balanced non linear load; as a result of this following results are obtained.

Following figure 6 shows three phase source voltages.

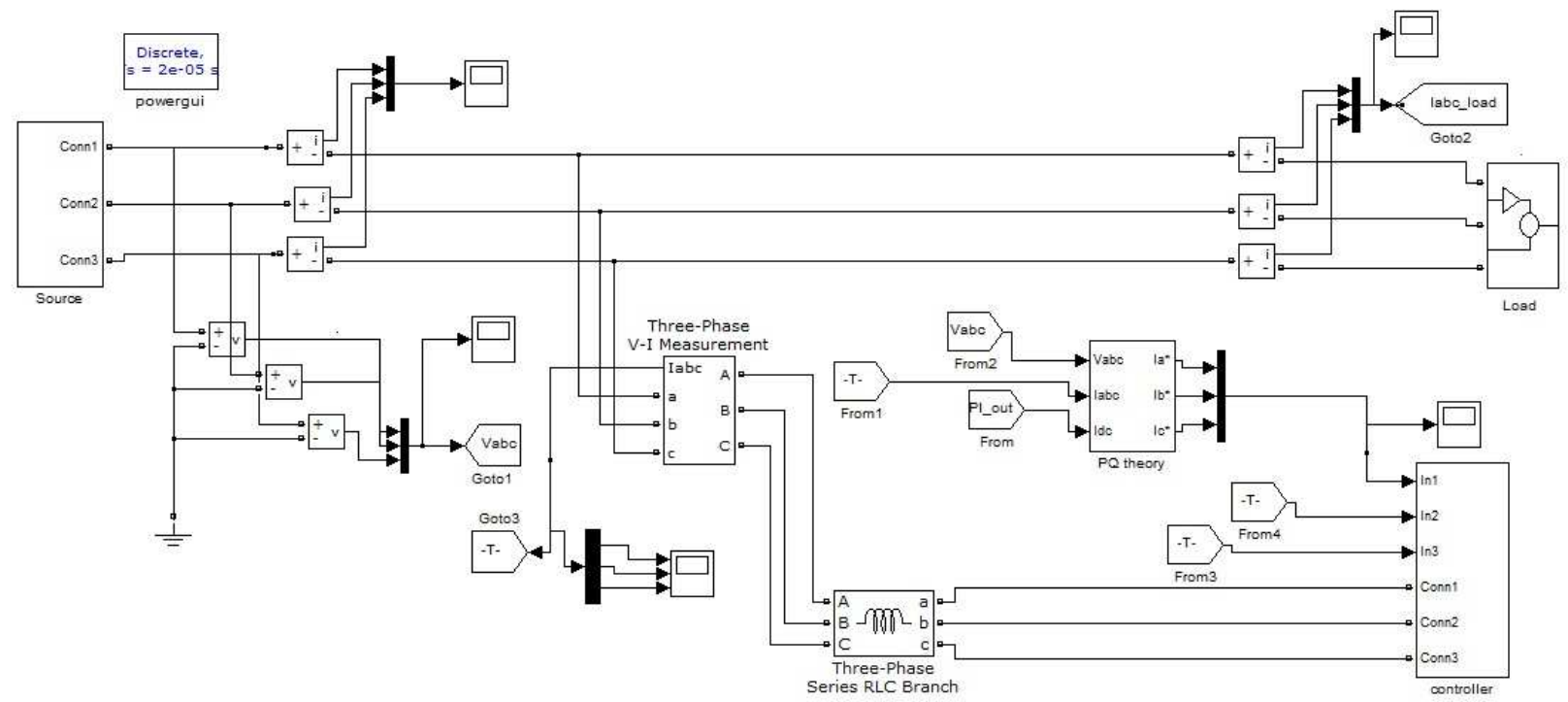

Figure5. MATLAB model of shunt active power filter 
International Journal of Trend in Scientific Research and Development (IJTSRD) ISSN: 2456-6470

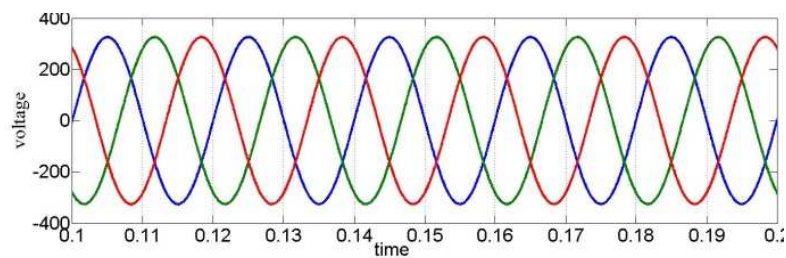

Figure6.Three phase Source voltages

Following figure 7 and 8 shows source current for three phases before compensation and after compensation.

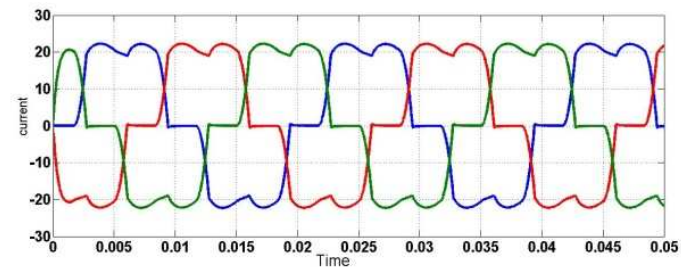

Figure7. Source current before compensation

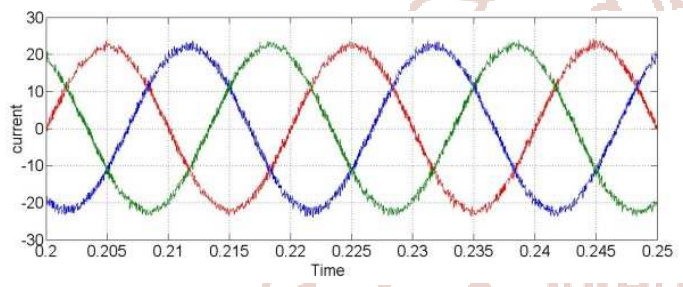

Figure8. Source current after compensation

The load current for three phases is obtained as fallows in figure 9 . Also filter current for three phases is obtained as fallows in figure 10 ,

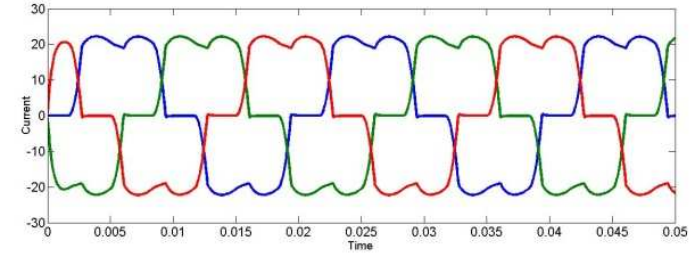

Figure9. Three phase load Current

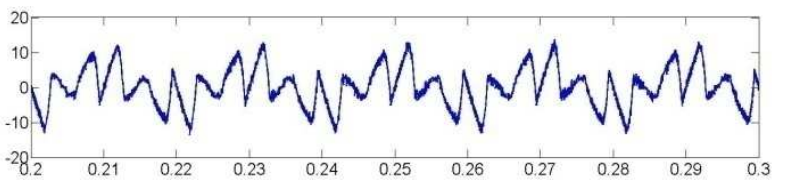

Figure 10. Filter current for three phases

THD of the given system shown in figure 11 below, THD is found to be $2.91 \%$

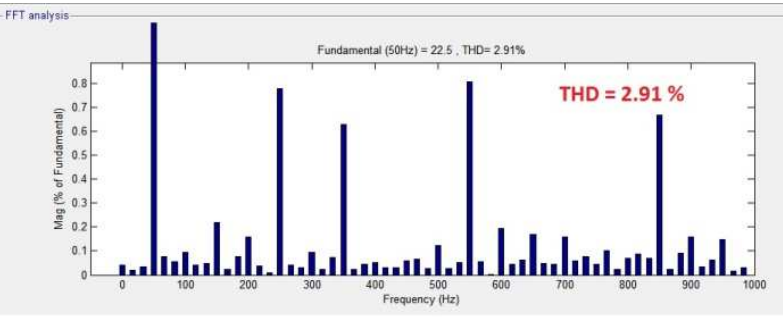

Figure11. THD of system

\section{CONCLUSION}

The key factor for successful performance of SAPF is reference current. The reference current using instantaneous reactive power theory is presented in this paper. Reference current is further used for generation of gating pulses. SAPF helps in reducing total harmonic distortion and maintain it to acceptable level. SAPF helps in improving power quality. The simulation results using MATLAB/simulink verifies that. The advantage of IRP theory is that it is to implement, less mathematical calculations. IRP or $\mathrm{p}-\mathrm{q}$ theory can effectively and efficiently be used to control shunt active power filters.

\section{REFERENCES}

1. M. Waware, P. Agarwal, "A Review of multilevel Inverter Based Active Power Filter", International Journal of Computer and Electrical Engineering, Vol. 3, No. 2, April, 2011 1793-8163196

2. Musa Yusup Lada, Ismadi Bugis, Md Hairu INizamTalib, "Simulation a Shunt Active Power Filter using MATLAB/Simulink" , The 4th International Power Engineering and Optimization Conf. (PEOCO2010), Shah Alam, Selangor, MALAYSIA: 23-24 June 2010

3. Bollen, M.H. (1999)," Understanding Power Quality Problems: Voltage Sags and Interruption”. Wiley-IEEE Press, ISBN 0-78034713-

4. M. A. Farahat , A. Zobah ," ACTIVE FILTER FOR POWER QUALITY IMPROVEMENT BYARTIFICIAL NEURAL NETWORKS TECHNIQUE" Zagazig University, Zagazig Egypt

5. María Isabel Milanés Montero, Enrique Romero Cadaval, Fermín Barrero González, "Comparison of Control Strategies for Shunt Active Power Filters in Three-Phase Four-Wire Systems", IEEE transactions on power electronics, vol. 22, no. 1, january 2007

6. Hirofumi Akagi, Hyosung Kim, "The Instantaneous Power Theory on the Rotating p-q-r Reference Frames" ,IEEE 1999 International Conference on Power Electronics and Drive Systems, PEDS'99, July 1999, Hong Kong

7. Smita Singhai, Bharti Dewani, "Implementation of Active Harmonic Filter with MATLAB/Simulink to compensate Non-Linear Loads", International Journal of Digital 
International Journal of Trend in Scientific Research and Development (IJTSRD) ISSN: 2456-6470

Application and Contemporary research, Volume 1, Issue 9, April 2013

8. Maoh-Chin Jiang, "Analysis and Design of a Novel Three-Phase Active Power Filter", IEEE transactions on aerospace and electronic systems vol. 37 , no. 3 july 2001

9. Jaime Prieto, Patricio Salmerón, Reyes S. Herrera, "Practical Design of a Load Compensation Active Conditioner", project by the CICYT (Ministerio de Ciencia yTecnología, Spain).

10. Bhim Singh and JitendraSolanki," A Comparison of Control Algorithms for DSTATCOM" IEEE transactions on industrial electronics, vol. 56, no. 7, july 2009.

11. Bhim Singh ,JitendraSolanki," An Implementation of an Adaptive Control Algorithm for a Three-
Phase Shunt Active Filter" IEEE transactions on industrial electronics, vol. 56, no. 8, august 2009

12. N. Mendalek, K. AI-Haddad, F. Fnaiech and L. A. Dessain, "Nonlinear control technique to enhance dynamic performance of a shunt active power filter" IEE Proceedings online no. 20030488 doi: 10.1049/ip-epa:20030488 21st May 2003

13. Roger C. Dugan, Mark F. McGranaghan, $H$. Wayne Beaty: Electrical Power Systems quality. New York : McGraw Hill, c1996

14. J. Arrillaga, N. R. Watson, S. Chen: Power System Quality Assessment. New York : John Wiley, c2000

15. Ewald F. Fuchs, Mohammad A. S. Masoum: Power Quality in Power Systems and Electrical Machines. Elsevier Academic Press, c2008 